\title{
SINGLE-MOLECULE DETECTION AND MANIPULATION WITH BIOLOGICAL NANOPORES
}

\author{
IRINA SCHIOPU ${ }^{\mathrm{a},{ }^{,},}$, ALINA ASANDEI ${ }^{\mathrm{a}}$, LOREDANA MEREUTA ${ }^{\mathrm{b}}$, \\ ISABELA DRAGOMIR ${ }^{\mathrm{a}}$, CEZARA BUCATARU ${ }^{\mathrm{b}}$, TUDOR LUCHIAN ${ }^{\mathrm{b}, *}$
}

\begin{abstract}
Single-molecule electrophysiology techniques using proteinbased or solid-state nanopores as nanoreactors were proven incredibly useful as platforms for sensing and biophysical characterisation of biological molecules (e.g., peptides, proteins), DNA detection and sequencing in a label-free, low-cost, rapid and high signal-to-noise ratio manner. Herein we present a number of discoveries in this field, developed over the years in our laboratory, including: (i) the $\mathrm{pH}$-mediated, fine-tuning of peptides passage through the $\alpha$-hemolysin nanopore; (ii) increase of the capture rate and dwell times of polypeptides inside the nanopore, through engineering dipole-like polypeptides; (iii) the implication of a nanopore-AuNP (citrate anion-coated gold nanoparticles) platform to selectively detect nanomolar concentrations of target ssDNA.
\end{abstract}

Keywords: single-molecule, peptides, electrophysiology, detection, sensing, nanopore, DNA, PNA

\section{INTRODUCTION}

Wild-type or genetically modified biological nanopores [1], [2], have been used as nanoreactors in various applications involving detection [3], sensing and identification [4], quantification [5], and physical characterization of single small molecules [6], [7].

Presently, among the most common biological nanopores we mention aerolysin [8]-[10], M. smegmatis porin A (MspA) [11], outer membrane protein $G$ (OmpG) [12], [13], fragaceatoxin C (FraC) [14], cytolysin A (ClyA) [15], 29 phage DNA packaging motor [16], outer membrane protein $\mathrm{F}(\mathrm{OmpF})$ [17]-[20].

a Alexandru Ioan Cuza University, Interdisciplinary Research Institute, Sciences Department, 54 Lascar Catargi str., RO-700107 lasi, Romania

b Alexandru Ioan Cuza University, Department of Physics, 11 Carol I bvd., RO-700506 lasi, Romania

* Corresponding authors: iri.schiopu@gmail.com, luchian@uaic.ro 
The alpha-hemolysin $(\alpha-H L)$, secreted by the human pathogen Staphylococcus Aureus, is one of the most often used nanopore in singlemolecule analysis techniques. A homo-heptameric (232.4 kDa) transmembrane channel is formed spontaneously when its water-soluble monomers bind to the surface of lipid membranes [21]. The resolved crystal structure of the $\alpha-\mathrm{HL}$ nanopore revealed three main structural componens: (i) the vestibule, with a $\sim 2.6 \mathrm{~nm}$ diameter opening; (ii) the lumen, a $\beta$-barrel segment having a $\sim 2 \mathrm{~nm}$ diameter opening, and (iii) the constriction region, with the narrowest diameter of $1.4 \mathrm{~nm}$ delimiting the vestibule from the lumen [22].

The interaction pathway of the studied molecules inside the nanopore depends greatly on which opening of the nanopore they enter. For example, based solely on steric considerations, the $\alpha-\mathrm{HL}$ nanopore's vestibule region allows entry of a B-form DNA-DNA duplex (diameter of $\sim 2 \mathrm{~nm}$ ), while the nanopore's $\beta$-barrel allows only single-stranded DNAs (diameter of $\sim 1 \mathrm{~nm}$ ) capture and passage [23], [24]. In the realm of nucleic acids analysis and among others, the $\alpha-\mathrm{HL}$ nanopore has proven efficient for the identification of individual microRNAs through the detection of a complex formed by the microRNA with a complementary RNA probe [25], base-pair energies calculus [26], in the determination of a DNA hairpin or a DNA-PNA duplex strength and in discriminating between hairpins or duplexes that differ by one base pair only [27]-[29].

The technique uses an external applied electric force to capture the molecule of interest inside the nanopore and, thus, reveal the specific features of the molecule (e.g., binding rate constants, apparent occupied volumes, binding energy, hybridization state, mismatching of base-pairs). In brief, the detection paradigm implicates the existence of a nanopore embedded in a stable artificial lipid bilayer [30] that separates the two sides of the recording cell, conventionally named, cis-side, ground connected, and trans-side, where the reference electrode is placed. Once a potential difference is applied on the protein-lipid system, the electrically charged particles from the buffer solution present in the two chambers will move across the nanopore driven by the generated electric field (Figure 1A, panel a) and a constant ionic current will be recorded (this represents the baseline of every control experiment, Figure $1 \mathrm{~A}$, panel c). As the molecule of interest is captured by the nanopore (Figure 1A, panel b), it will transiently block it and such events are seen as reversible decreases in the ionic current flow. The main parameters important to be monitored and analyzed in this context, which shed light of molecule's features or its interaction with the nanopore, are: (1) $\tau_{\text {on }}$ - the average inter-blocking events time; (2) $\tau_{\text {off }}$ - the dwell time of the molecule inside the nanopore and (3) $\Delta \mathrm{l}$ - the average current blockade caused by the presence of a single molecule inside the nanopore, which is usually calculated as the modulus of the difference between the baseline current (lopen) and the value of the blockage values (l $\mathrm{I}_{\text {blocked }}$ ) (Figure 1A, panel d). 


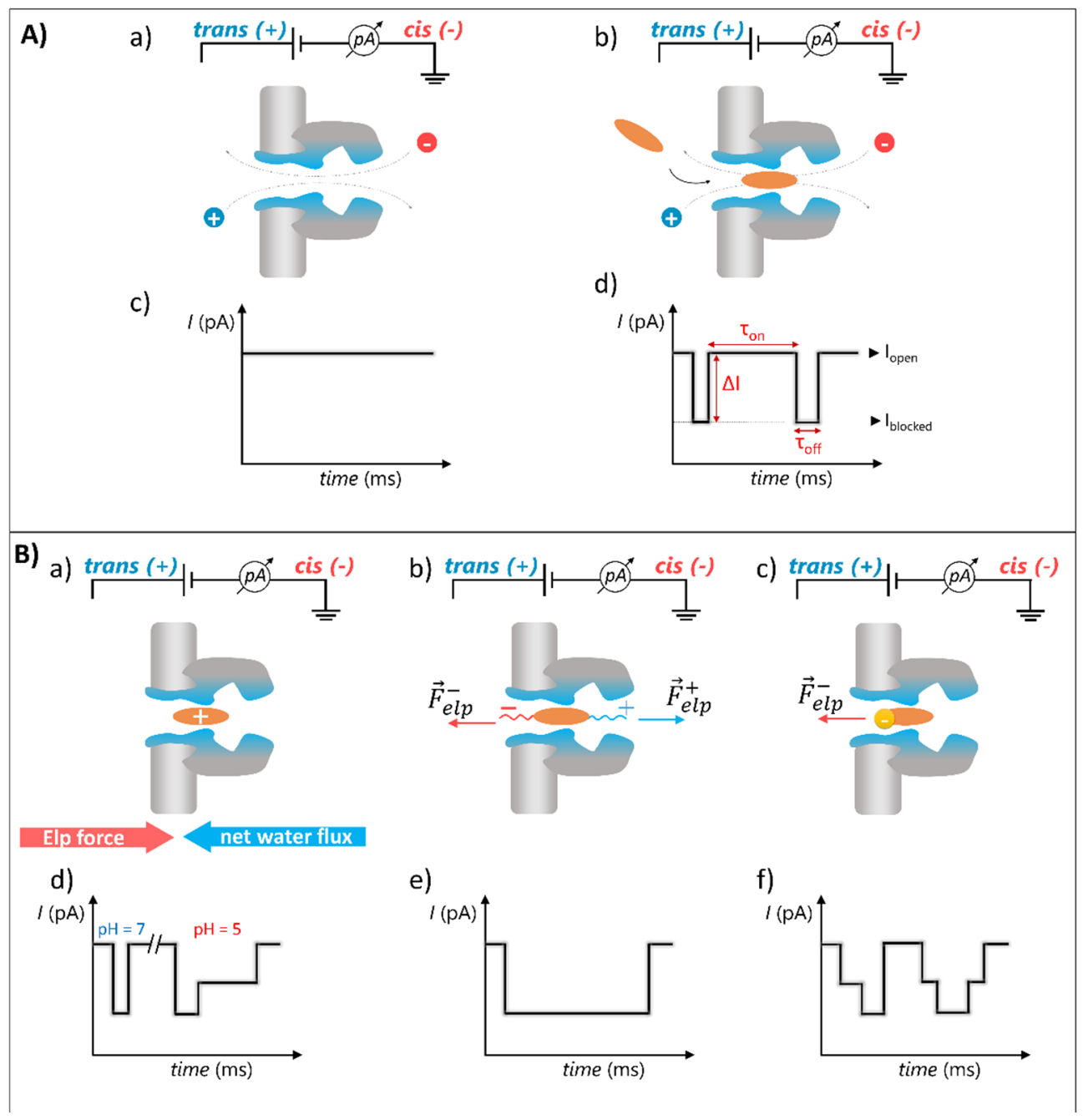

Figure 1. A) Schematic representation of the single-molecule detection technique using the $\alpha-\mathrm{HL}$ nanopore. The main principle of detection relies on monitoring the ionic current through the nanopore (panels a and c) and observing the fluctuations in the ionic current determined by the passing of a molecule through the nanopore (panels $b$ and $d$ ) and analyzing the specific interaction parameters (panel d) B) Schematic representations of ways to optimize the single-molecule detection technique: slowing down the passage of the studied molecule through the nanopore by enhancement of the electro-osmotic flow via $\mathrm{pH}$ fine-tuning (panel $\mathrm{a}$ and $\mathrm{d}$ ); functionalization of the biomolecule with oppositely charged segments (panels $b$ and e); using citrate anion-coated gold nanoparticles (yellow circles in panel $c$ ) in order to reveal the specific fingerprint of single molecules or molecular complexes (e.g., ssDNA, DNA-PNA duplex) (panel f). 
Several enhancement strategies can be used in order to improve the sensitivity and the resolution of the detection approach. As investigated in our laboratory, these 'gimmicks' imply slowing down the passage of the molecule through the nanopore or make use of charged ligands to enhance the detection of the target molecule.

The first approach focuses on keeping the molecule inside the nanopore for a longer period of time either by modifying the $\mathrm{pH}$ values of the solution in which the protein-lipid system is placed, thus altering the electroosmotic flow and rendering it opposite to the electrophoretic flow at acidic $\mathrm{pH}$ values and thereby exerting a better control over the molecule translocation across the nanopore (Figure 1B, panels a and d). Alternatively, by engineering biomolecules (e.g., polypeptides or peptide-nucleic acids - PNAs) with oppositely charged amino acids segments at both termini, their collective interaction with the applied transmembrane potential determine electrophoretic forces pulling oppositely on the nanopore-captured biopolymer and prolong its dwell times inside the nanopore (Figure 1B, panels $b$ and e).

The second approach focuses on the specific ionic current signature of the molecule upon interaction with the nanopore (Figure 1B, panel $c$ and $f$ ). The use of unmodified citrate anion-coated gold nanoparticles (AuNPs) can help detect small quantities of target molecules like ssDNA of more complex compounds like hybridize DNA-PNA molecules.

Regardless of the chosen approach, the main purpose of such enhancement strategies is to lead to a rapid, real-time, low-cost, label-free detection technique with high sensitivity and resolution.

\section{STRATEGIES FOR SLOWING DOWN MOLECULES THROUGH A PROTEIN NANOPORE}

\section{pH-mediated fine-tuning of forces exerted on the nanopore- captured peptide reveals intermediate states in peptide translocation}

The principle of this strategy was applied in our lab in the study of chimeric peptides termed CAMA, a merge between the sequences of the antimicrobial peptides cecropin A (CA) and magainin (MA) (Table 1). By varying the solution $\mathrm{pH}$ ranging from neutral to mildly acidic values $(\mathrm{pH}=7.1$, $3.3,4.5,5.1$ ) the translocation speed of the peptide is decreased and different sub-states of the peptide's pathway inside the $\alpha-H L$ nanopore were identified (i.e., $\beta$-barrel vs. vestibule).

Table 1. The amino acid sequences of the peptides

\begin{tabular}{|c|c|}
\hline Peptides & Sequence \\
\hline CAMA P1 & KWKLFKKIGIGKHFLSAKKF-NH $H_{2}$ \\
\hline CAMA P5 & KWKHLKKIGIGKHFLSAKKF-NH 2 \\
\hline CAMA P6 & KWKLFKKIGIGKFLQSAKKF-NH ${ }_{2}$ \\
\hline
\end{tabular}


This approach led to the following findings: (1) the revealing of twosub-states corresponding to the location of the peptide inside the nanopore; (2) the capture rate of the peptide can be controlled by modifying the $\mathrm{pH}$; (3) the dwell time of the last sub-state, corresponding to the peptide in the vestibule part of the nanopore, increases at acidic $\mathrm{pH}$ [31].

The two main sub-states observed when decreasing the $\mathrm{pH}$ value of the solution, which are invisible at neutral $\mathrm{pH}$, are denoted in Figure 2 with $\mathrm{B} 1$, representing the blockade produced by the presence of the peptide inside the lumen ( $\beta$-barrel) part of the nanopore, and B2, representing the blockade of the vestibule part of the nanopore by the peptide's presence. As the CAMA P6 peptide was added in the trans-part of the lipid-nanopore system, the B1 blockade arises first, followed sequentially by the smaller B2 blockade substate, the direction of the peptide's movement inside the nanopore being trans $\rightarrow$ lumen $\rightarrow$ vestibule $\rightarrow$ cis. As the buffer $\mathrm{pH}$ is lowered from 5.1 to 3.3 , the second B2 blockade sub-state becomes more distinguishable (Figure 2, panel $a$ and $b$ ).
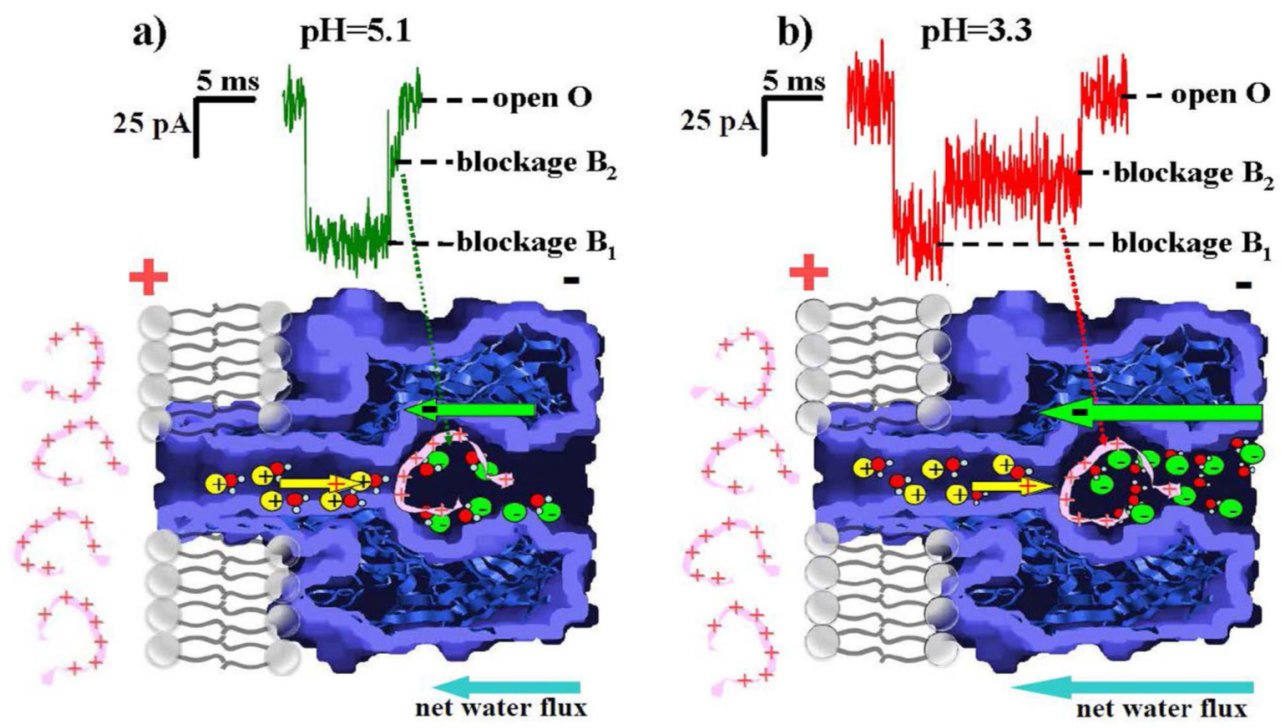

Figure 2. Representation of the two distinct blockade substates revealed by lowering the electrolyte's pH from 5.1 (panel a) to 3.3 (panel b). The open states are marked (open O) and the blockade sub-states by B1 (associated with a single CAMA peptide lodged inside the $\alpha$-HL's $\beta$-barrel) and respectively B2 (associated with a single CAMA peptide lodged inside the $\alpha$-HL's vestibule). The trans-added cationic CAMA peptide is depicted in pink. When the lipid membrane-isolated nanopore is positively biased, the peptides are electrophoretically driven inside the nanopore, while by lowering the $\mathrm{pH}$, the flux of anions transported in the opposite direction is higher than that of cations, rendering the overall net water flux opposite to the trans-to-cis movement of the peptide, thus increasing the translocation duration. Adapted from [31]. 
IRINA SCHIOPU, ALINA ASANDEI, LOREDANA MEREUTA, ISABELA DRAGOMIR, CEZARA BUCATARU, TUDOR LUCHIAN

The peptide capture by the nanopore can be controlled by modulating the $\mathrm{pH}$ value in the electrolyte

A side observation related to the $\mathrm{pH}$-controlled trafficking of studied peptides across the $\alpha-\mathrm{HL}$ nanopore, is a visible decrease in the CAMA peptide association rate with the nanopore at low pH values (Figure 3, panel a). This is a direct consequence of the repulsive electrostatic interactions which manifest at acidic $\mathrm{pH}$ between the positively charged peptide and the positive charges found at the mouth of the $\alpha-\mathrm{HL} \beta$-barrel.

\section{The peptide residence time inside the $\alpha-H L$ vestibule increase at acidic $\mathrm{pH}$}

The B2 sub-state (Figure 3, panel c) which is associated with the peptide's dwelling inside the $\alpha$-HL's vestibule, increases dramatically at acidic $\mathrm{pH}$ values. In figure 3 , panel $b$, the statistical analysis of the dissociations rate $\left(\right.$ rate $_{\text {off }} \mathrm{B} 2=\tau_{\text {off }} B 2^{-1}$ ) as a function of $\mathrm{pH}$ are represented. Two main causes were proposed account for these observations: (1) the role of electrostatic repulsions forces between the cationic peptide and the protein inner surface positive charges or, (2) the increase of the electro-osmotic flow which opposes the electrophoretic force that drives the peptide through the nanopore.

a)

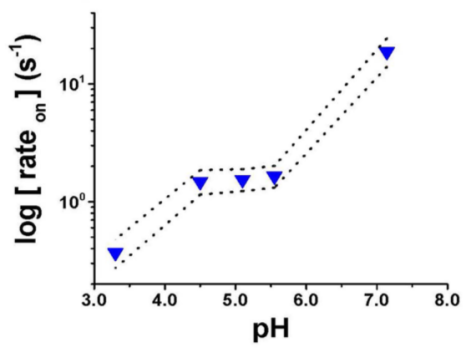

b)

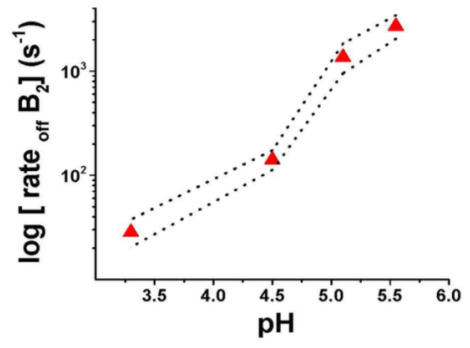

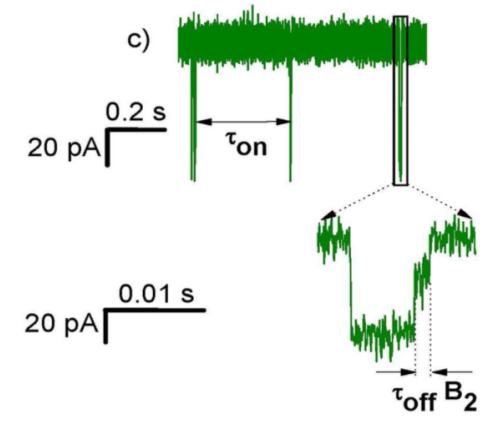

Figure 3. The effect of lowering the electrolyte's $\mathrm{pH}$ on the association rate (panel a) and dissociation rate (panel b), respectively, characterizing the reversible interactions between the cationic peptide and the vestibule region of the $\alpha-\mathrm{HL}$ nanopore (denoted by B2 in panel c). Adapted from [31]. 
The main role of the electrophoretic and electro-osmotic forces in slowing down the peptide drift velocity along the vestibule region of the $\alpha-H L$ nanopore

To explain how the interplay of the electrophoretic and electro-osmotic forces leads to the slowdown of the peptide movement inside the nanopore's vestibule, the following facts are to be considered: (1) the cationic peptide moves across the nanopore in the trans-to-cis direction, driven by the external applied electrophoretic force; (2) the $\alpha$-hemolysin nanopore is slightly anion selective at neutral $\mathrm{pH}$, and this augments at acidic $\mathrm{pH}$, causing the net water flow carried by anions to move in the cis-to-trans direction, making the electro-osmotic water flow to oppose electrophoresis. Collectively, the drift velocity of a peptide $\left(v_{\text {drift }}\right)$ can therefore be expressed as the vector sum of the electrophoretic and electroosmotic components [31]:

$$
v_{\text {drift }}=v_{\text {electrophoretic }}-v_{\text {electroosmotic }}=\mu \frac{\Delta V}{l_{\text {pore }}}-\frac{\left(P_{C l-}-P_{K+}\right)}{\left(P_{C l-}+P_{K+}\right)} N_{h} I /\left(\left|e^{-}\right| S_{\text {pore }}\left[H_{2} O\right]\right)
$$

where $\mu$ - peptide's electrophoretic mobility, $\Delta \mathrm{V}$ - the applied potential difference, $I_{\text {pore }}$ and $S_{\text {pore }}$ - length and average cross-section of the $\alpha-\mathrm{HL}$ nanopore vestibule, $\mathrm{P}_{\mathrm{K}+}$ and $\mathrm{P}_{\mathrm{Cl}-}-$ ionic permeabilities, $\mathrm{N}_{\mathrm{h}}$ - number of water molecules associated with each mobile ion, I - net ionic current through the nanopore while a peptide resides within the vestibule (i.e., B2 sub-state in figure 3, panel c), $|e-|$ - electronic charge, $\left[\mathrm{H}_{2} \mathrm{O}\right]$ - water concentration. The formula (1) clearly shows that as the nanopore increases its anion selectivity, the electro-osmosis flow will also increase, causing the drift velocity of the peptide to decrease. By tuning the $\mathrm{pH}$ value of the solution in which the lipidnanopore system is immersed, and thus modifying the net output between the electrophoretic and the electro-osmotic flow, it is possible to trap and identify in a very effective way nanoparticles [32], DNA fragments [33] or dendrimers [34], [35]. Also, further studies showed that at extreme acidic $\mathrm{pH}$ values the cationic peptides reveal a back-and-forth movement between the vestibule and the lumen region of the $\alpha-\mathrm{HL}$, before being released [36].

\section{Oppositely charged segments engineered on polypeptides slow- down their passage across the nanopore}

This strategy makes use of a design in the primary structure of polypeptides, by placing opposite charged groups (glutamic acids and arginines) at their $\mathrm{N}$ - and $\mathrm{C}$ - termini (Table 2).

Table 2. The primary sequences of the modified polypeptides

\begin{tabular}{|c|c|}
\hline Peptides & Sequence \\
\hline CP2a & $\mathrm{Ac}-(\mathrm{E})_{12}-(\mathrm{N})_{12}-(\mathrm{R})_{12}-\mathrm{NH}_{2}$ \\
\hline $\mathrm{CP} 2 \mathrm{~b}$ & $\mathrm{Ac}-(\mathrm{E})_{12}-(\mathrm{Q})_{12}-(\mathrm{R})_{12}-\mathrm{NH}_{2}$ \\
\hline
\end{tabular}


In this case, all studies were carried out at neutral $\mathrm{pH}$ (7.3) and the peptides were added in the trans-side of lipid membrane-nanopore system. The experiments revealed significant details about the kinetics of such new designed peptides while interacting with the nanopore: (1) the capture rate of peptide were enhanced by increasing the applied potential across the nanopore; (2) the main cause of the increase capture rate is the presence of the electrostatic attraction interactions between the polypeptide and the entry of the nanopore's $\beta$-barrel; (3) the dwell time of the captured peptide was increased by augmenting the applied transmembrane value [37].

a)

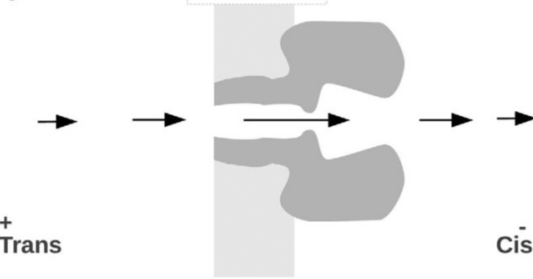

c)

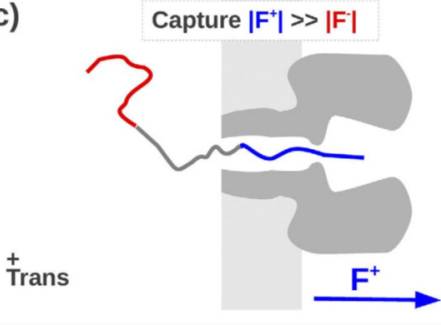

e)

Zero-force state $\left|F^{+}\right|=|F|$

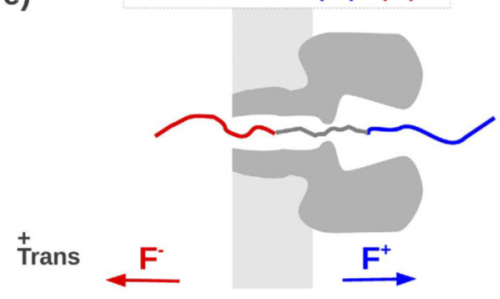

Cis b)

Alignment

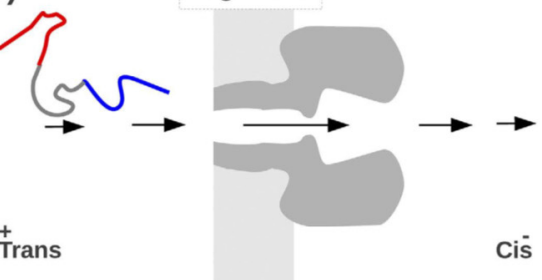

d)

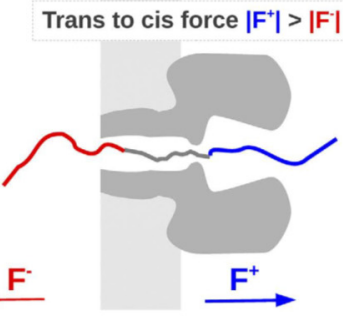

Cis

f)

Cis to trans force $\left|\mathrm{F}^{+}\right|<|\mathrm{F}|$

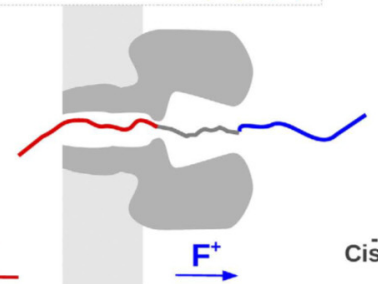

Figure 4. Descriptive model of a macrodipole-like polypeptide (red - negatively charged moiety, blue - positively charged moiety) movement inside the $\alpha-\mathrm{HL}$ nanopore isolated in a lipid membrane, under the influence of an applied transmembrane potential. Adapted from [37]. 
In Figure 4, the peptide's motion across the nanopore is illustrated in a simplest embodiment, depicting its journey across the nanopore's distinct regions. When the polypeptides were added in the trans-side of the nanopore, a positively applied transmembrane potential will orient a nanopore approaching polypeptide, to enter the $\beta$-barrel with its negative tail head on (i.e., glutamic acids segment) (Figure 4, panel b). Note that the electro-osmotic flow effects can be neglected, as such the experiments were carried out at neutral $\mathrm{pH}$ [31]. This event marks the polypeptide capture (Figure 4, panel c), continued by its movement inside the nanopore, driven by a net electric force stemming from components acting on the two oppositely charged tails (Figure 4, panel d). When a balance between the two electric forces acting on the captured polypeptide is reached (zero-force state), a metastable state ensues (Figure 4, panel e) that can be maintained until thermal fluctuations break it and lead to the polypeptide's escape (Figure 4, panel f). Through entrapping a captured polypeptide for a longer time inside the nanopore, this strategy facilitated monomers discrimination on the polypeptide sequence [38-40].

We have also shown that the capture rate and the residence time of the different biomolecules can be controlled by applying a salt gradient across the nanopore. By using a lower salt concentration in the side where the molecules were being added, the detection of the biomolecules can be significantly enhanced without reducing the residence times [41] and even increase the detection sensitivity in the nanomolar range of studied molecule [27].

\section{STRATEGIES FOR DETECTING SINGLE-STRANDED DNA AND PNA MOLECULES}

The nanopore-based strategy enabling single-stranded DNA (ssDNA) and DNA-PNA molecular complexes detection with unmodified citrate anioncoated gold nanoparticles (AuNPs), is based upon the following pillars: (1) each specific molecule or molecular complex has its own distinguishable signature in the recorded ionic current across the nanopore; (2) the AuNPs undergo aggregation upon interacting with the neutrally charged PNA molecules, thus changing the pattern of the ionic current fluctuations as compared to control experiments (present only AuNPs); (3) the PNA-DNA hybridization process disrupts the AuNPs aggregation, and this is distinguishable via electric current measurements through the nanopore (Figure $5 \mathrm{I}$ ) [42]. The selected PNA and ssDNAs sequences chosen for such experiments are presented in Table 3, where HCV is a specific sequence to the hepatitis $C$ virus and H1N1 is a specific ssDNA sequence to a type of influenza A virus [43]. 
IRINA SCHIOPU, ALINA ASANDEI, LOREDANA MEREUTA, ISABELA DRAGOMIR, CEZARA BUCATARU, TUDOR LUCHIAN

Table 3. The primary sequences of the polynucleotides (PNA and ssDNA)

\begin{tabular}{|c|c|}
\hline Polynucleotide & Sequence \\
\hline PNA2 & $5^{\prime}$-CCCACCCGCAGCCCTCATTA-3' \\
\hline $\begin{array}{c}\text { HCV (ssDNA complementary } \\
\text { to PNA2) }\end{array}$ & $5^{\prime}$-TAATGAGGGCTGCGGGTGGG-3' \\
\hline $\begin{array}{c}\text { H1N1 (ssDNA non- } \\
\text { complementary to PNA2) }\end{array}$ & 5'-ACG GAAGGA GTGCCAA-3' $^{\prime}$ \\
\hline
\end{tabular}

We envisioned that ionic current fluctuations recorded through the nanopore were specific to the cis-side addition of AuNP alone (Figure 5II, panel a), PNA2 (Figure 5II, panel b), HCV and H1N1 (Figure 5II, panel c). Moreover, to preclude the fast salt-induced aggregation of AuNPs and enhance at the same time the sensitivity of the detection process [44], a salt-gradient was maintained across the nanopore (trans $3 \mathrm{M} \mathrm{KCl}$, cis $0.1 \mathrm{M} \mathrm{KCl}$ ).

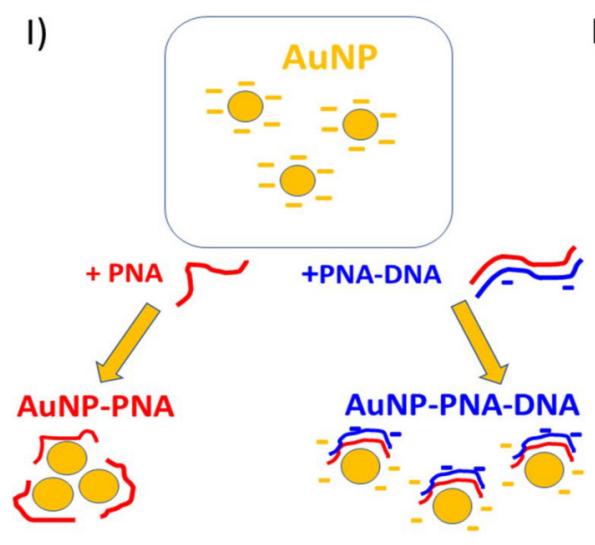

II)

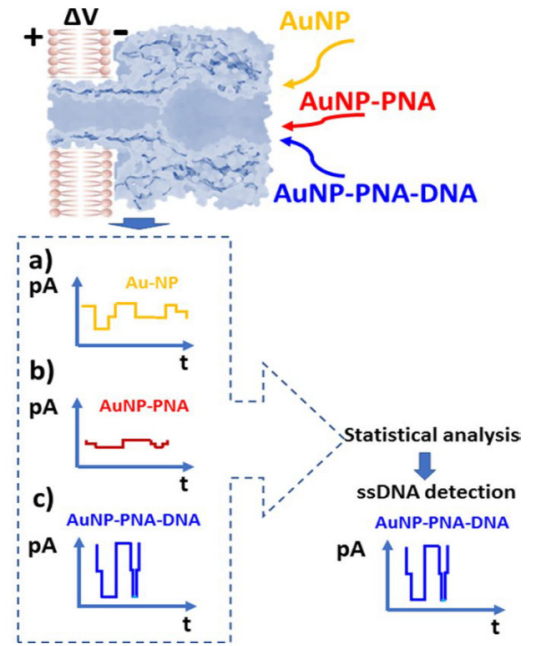

Figure 5. The ssDNAs and DNA-PNA complexes detection strategy using an AuNP-nanopore platform. (I) AuNP-PNA form aggregates that can be disrupted by the hybridization process of PNAs molecules with the complementary ssDNAs. (II) Each analyte entails a distinguishable ionic current blockade signature through the $\alpha-\mathrm{HL}$ nanopore (AuNPs - panel a AuNP-PNA aggregates - panel $b$ and AuNP-PNA-DNA complexes - panel c), thus facilitating ssDNA detection when using PNA with a complementary sequence. Adapted from [42].

As evidenced in figure 6, summarizing experiments whereby the analytes were added successively in the cis-side of the membrane (AuNPs (panel a), PNA2 (panel b), H1N1 (panel c) and HCV (panel d), distinct patters in the current fluctuations can be observed, visible from the amplitude analysis and the average dwell times (Table 4). 
Table 4. Concentration values, ionic current blockages and dwell times for AuNP, and the consecutively added PNA2, H1N1 and HCV

\begin{tabular}{|l|c|c|c|}
\hline & Concentration & $\Delta \mathrm{l}(\mathrm{pA})$ & $\tau_{\text {off }}(\mathrm{s})$ \\
\hline AuNP & $5 \mathrm{nM}$ & $48.1 \pm 0.85$ & $0.001 \pm 5 \mathrm{E}-4$ \\
\hline AuNP/PNA2* & $5 \mathrm{nM}$ & - & - \\
\hline AuNP/PNA2/H1N1 & $15 \mathrm{nM}$ & $57.3 \pm 0.8$ & $0.0016 \pm 0.001$ \\
\hline AuNP/PNA2/H1N1/HCV & $50 \mathrm{nM}$ & $15.4 \pm 0.4$ & $0.12 \pm 0.01$ \\
\hline
\end{tabular}

* no values recorded, because the AuNP/PNA aggregates were precluded from entering the nanopore, due to steric exclusion

The recorded data demonstrate the possibility of detecting singlestranded HCV fragments in the presence of other ssDNA sequences (i.e., H1N1), mimicking a heterogenous nucleic acids sample.

a) $A u N P$

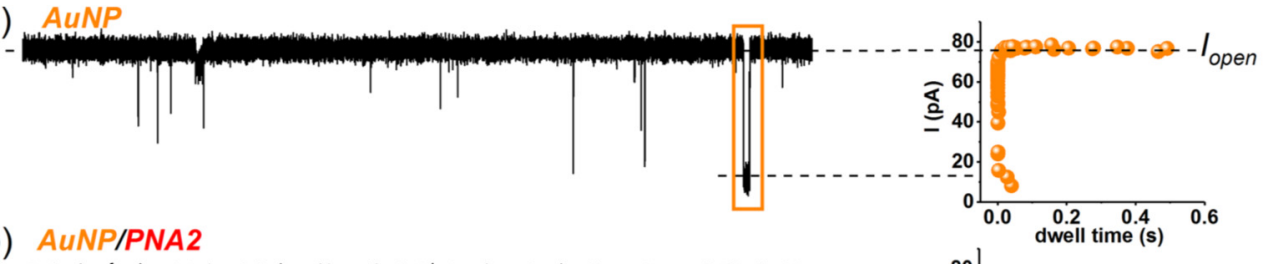

b) AuNPIPNA2

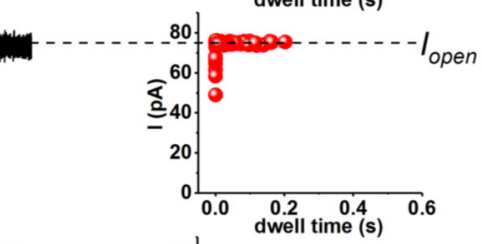

c) AuNP/PNA2/H1N1

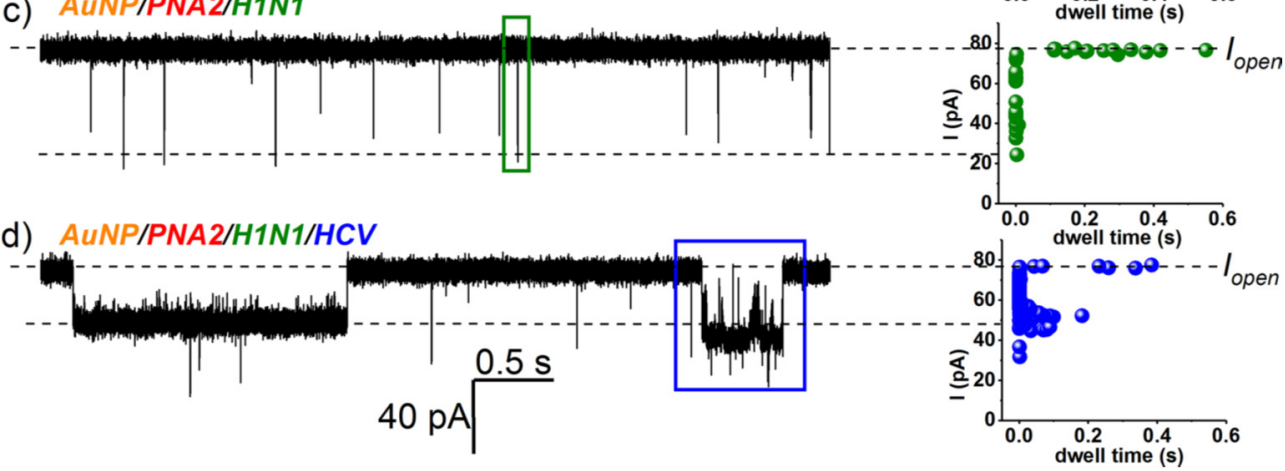

Figure 6. Ionic current fluctuation recorded at $\Delta \mathrm{V}=+70 \mathrm{mV}$ in the presence of the cis-added AuNPs alone (5 nM) (a), AuNPs mixed with PNA (5 nM) (b), AuNPs/PNA aggregates in the presence of H1N1 (15 nM) (c) and AuNPs/PNA in the presence of both $\mathrm{H} 1 \mathrm{~N} 1(15 \mathrm{nM})$ and HVC $(50 \mathrm{nM})(\mathrm{d})$, as well as their corresponding current amplitude histograms. Adapted from [42]. 
IRINA SCHIOPU, ALINA ASANDEI, LOREDANA MEREUTA, ISABELA DRAGOMIR, CEZARA BUCATARU, TUDOR LUCHIAN

The minimum concentration detection limit for PNA2, HCV and H1N1 was established in the nanomolar range $(5 \mathrm{nM})$.

\section{CONCLUSIONS}

Unlike other simple, conventional approaches to probing biopolymers properties and function in reconstituted lipid membranes [45], a grand challenge in today's proteomics and genomics is to correlate structure with function, via single-molecule studies. An essential step to achieve individual biopolymers detection and sequencing with single monomer resolution, lies in the specific capturing and holding of polymers inside the nanopore for sufficiently long periods of time, to enable accurate sequence readout. Herein we presented only a few selected from the emerging technologies developed in our laboratory, still in the proof-of-concept stage, yet holding a promise to that end. In the realm of nucleic acids detection, the AuNP aggregation strategy working in conjunction with PNA fragments and nanopore sensing, may enable the rapid and reliable nucleic acid diagnosis, with minimum number of specialized reagents involved.

We dedicate this work to the memory of Professor Petre T. Frangopol, whose work, struggle and dedication made possible the introduction of Biophysics and Medical Physics fields at the Faculty of Physics, 'Alexandru I. Cuza' University of lasi.

\section{ACKNOWLEDGMENTS}

This work was largely supported by grants PN-III-P1-1.1-TE-20190037, PN-III-P2-2.1-PED-2019-0016, PN-III-P4-ID-PCE-2020-0011.

\section{REFERENCES}

1. J. J. Kasianowicz; J. W. F. Robertson; E. R. Chan; J. E. Reiner; V. M. Stanford, Annu. Rev. Anal. Chem. 2008, 1, 737-766

2. S. W. Kowalczyk; T. R. Blosser; C. Dekker; Trends Biotechnol., 2011, 29, 607614

3. Z.-L. Hu; M.-Z. Huo; Y.-L. Ying; Y.-T. Long; Angew. Chem. Int. Ed., 2021, 10.1002/anie.202013462

4. A. Asandei; S. Iftemi; L. Mereuta; I. Schiopu; T. Luchian; J. Membr. Biol., 2014 247(6), 523-530 
SINGLE-MOLECULE DETECTION AND MANIPULATION WITH BIOLOGICAL NANOPORES

5. J. J. Kasianowicz; E. Brandin; D. Branton; D. W. Deamer; Proc. Natl. Acad. Sci. USA, 1996, 93, 13770-13773

6. T. Luchian; Y. Park; A. Asandei; I. Schiopu; L. Mereuta; A. Apetrei; Acc. Chem. Res., 2019, 52 (1), 267-276

7. A. Asande; I. Schiopu; S. Iftemi; L. Mereuta; T. Luchian; Langmuir, 2013, 29, 15634-15642

8. A. Fennouri; R. Daniel; M. Pastoriza-Gallego; L. Auvray; J. Pelta; L. Bacri; Anal. Chem., 2013, 85, 8488-8492

9. C. Cao; J. Yu; Y.-Q. Wang; Y.-L. Ying; Y.-T. Long; Anal. Chem., 2016, 88, 50465049

10. C. Cao; M.-Y. Li; N. Cirauqui; Y.-Q. Wang; M. Dal Peraro; H. Tian; Y.-T. Long; Nat. Commun., 2018, 9, 2823

11. T. Z. Butler; M. Pavlenok; I. M. Derrington; M. Niederweis; J. H. Gundlach; Proc. Natl. Acad. Sci. USA, 2008, 105, 20647-20652

12. S. Conlan; Y. Zhang; S. Cheley; H. Bayley; Biochemistry, 2000, 39, 1184511854

13. M. Chen; S. Khalid; M. S. P. Sansom; H. Bayley; PNAS, 2008, 105, 6272-6277

14. G. Huang; K. Willems; M. Soskine; C. Wloka; G. Maglia; Nat. Commun., 2017, 8,1

15. M. Soskine; A. Biesemans; B. Moeyaert; S. Cheley; H. Bayley; G. Maglia; Nano. Lett., 2012, 12, 4895-4900

16. F. Haque; J. Lunn; H. Fang; D. Smithrud; P. Guo; ACS Nano, 2012, 6, 32513261

17. E. M. Nestorovich; T. K. Rostovtseva; S. M. Bezrukov; Biophys. J., 2003, 85, 3718-3729

18. E. M. Nestorovich; C. Danelon; M. Winterhalter; S. M. Bezrukov; Proc. Natl. Acad. Sci. USA, 2002, 99, 9789-9794

19. A. Apetrei; A. Asandei; Y. Park; K.-S. Hahm; M. Winterhalter; T. Luchian; J. Bioenerg. Biomembr., 2010, 42, 173-180

20. J. Wang; J. A. Bafn; S. P. Bhamidimarri; M. Winterhalter; Angew. Chem. Int. Ed., 2019, 58, 4737-4741

21. K. Yamashita; Y. Kawai; Y. Tanaka; N. Hirano; J. Kaneko; N. Tomita; M. Ohta; Y. Kamio; M. Yao; I. Tanaka; Proc. Natl. Acad. Sci. USA, 2011, 108, 1731417319

22. L. Song; M. R. Hobaugh; C. Shustak; S. Cheley; H. Bayley; J. E. Gouaux; Science, 1996, 274, 1859-1865

23. L.-Q. Gu; J. W. Shim; Analyst, 2010, 135, 441-451

24. R. T. Perera; A. M. Fleming; A. M. Peterson; J. M. Heemstra; C. J. Burrows; H. S. White; Biophys. J., 2016, 110, 306-314

25. Y. Wang; D. Zheng; Q. Tan; M. X. Wang; L.-Q. Gu; Nat. Nanotechnol., 2011, 6, 668-674

26. A. Ciuca; A. Asandei; I. Schiopu; A. Apetrei; L. Mereuta; C. H. Seo; Y. Park; T. Luchian; Anal. Chem., 2018, 90, 7682-7690

27. L. Mereuta; A. Asandei; I. Schiopu; Y. Park; T. Luchian; Anal. Chem., 2019, 91, 8630-8637 
IRINA SCHIOPU, ALINA ASANDEI, LOREDANA MEREUTA, ISABELA DRAGOMIR, CEZARA BUCATARU, TUDOR LUCHIAN

28. W. Vercoutere; S. Winters-Hilt; H. Olsen; D. Deamer; D. Haussler; M. Akeson; Nat. Biotechnol., 2001, 19, 3

29. Y. Ding; A. M. Fleming; H. S. White; C. J. Burrows; J. Phys. Chem. B, 2014, 118, 12873-12882

30. M. Montal; P. Mueller; Proc. Natl. Acad. Sci. USA, 1972, 69, 3561-3566

31. L. Mereuta; M. Roy; A. Asandei; J. K. Lee; Y. Park; I. Andricioaei; T. Luchian; Sci. Rep., 2014, 4, 3885

32. M. Tsutsui; Y. Maeda; Y. He; S. Hongo; S. Ryuzaki; S. Kawano; T. Kawai; M. Taniguchi; Appl. Phys. Lett., 2013, 103, 013108

33. Y. He; M. Tsutsui; C. Fan; M. Taniguchi; T. Kawai; ACS Nano, 2011, 5, 55095518

34. A. Asandei; A. Ciuca; A. Apetrei; I. Schiopu; L. Mereuta; C. H. Seo; Y. Park; T. Luchian; Sci. Rep., 2017, 7, 6167

35. A. Asandei; I. Schiopu; C. Ciobanasu; Y. Park; T. Luchian; J. Membr. Biol., 2018, $251,405-417$

36. A. Asandei; I. Schiopu; M. Chinappi; C. H. Seo; Y. Park; T. Luchian; ACS Appl. Mater. Interfaces, 2016, 8, 13166-13179

37. A. Asandei; M. Chinappi; J. -K. Lee; C. H. Seo; L. Mereuta; Y. Park; T. Luchian; Sci. Rep., 2015, 5, 10419

38. I. S. Dragomir; A. Asandei; I. Schiopu; I. C. Bucataru; L. Mereuta; T. Luchian; Polymers (Basel), 2021, 13, 1210

39. A. Asandei; G. Di Muccio; I. Schiopu; L. Mereuta; I. S. Dragomir; M. Chinappi; T. Luchian; Small Methods, 2020, 4, 1900595

40. A. Asandei; I. S. Dragomir; G. Di Muccio ;M. Chinappi; Y. Park; T. Luchian; Polymers (Basel), 2018, 10, 885

41. M. Wanunu; W. Morrison; Y. Rabin; A. Y. Grosberg; A. Meller; Nat. Nanotechnol., 2010, 5, 160-165

42. L. Mereuta; A. Asandei; I. S. Dragomir; I. C. Bucataru; J. Park; C. H. Seo; Y. Park; T. Luchian; Sci. Rep., 2020, 10, 11323

43. Z. Guan; J. Liu; W. Bai; Z. Lv; X. Jiang; S. Yang; A. Chen; G. Lv; PLOS ONE, 2014, 9, e108401

44. L. Mereuta; A. Asandei; C. H. Seo; Y. Park; T. Luchian; ACS Appl. Mater. Interfaces, 2014, 6, 13242-13256

45. L. Mereuta; T. Luchian; Y. Park; K.-S. Hahm; Biochem. Biophys. Res. Commun., 2008, 373, 467-472 